Антипин Иван Александрович

кандидат экономических наук, доцент, доцент кафедры региональной, муниципальной экономики и управления

Уральского государственного

экономического университета

\section{ЦИФРОВИЗАЦИЯ КАК ИНСТРУМЕНТ ТРАНСФОРМАЦИИ СТРАТЕГИЧЕСКОГО РАЗВИТИЯ ТЕРРИТОРИИ [1]}

\begin{abstract}
Аннотация:
Статья посвящена исследованию цифровизации как инструмента достижения и трансформации приоритетов стратегического развития территории. Представлены стратегические цели и приоритетные направления развития Российской Федерации. Исследованы возможности развития процессов иифровизации в городе Екатеринбурге. Методоло гическая база исследования основывается на теоретических положениях стратегического менеджмента, региональной и пространственной экономики. Подходы российских ученых к стратегиям и цифровой экономике раскрыты путем использования совокупности методов: логического, диалектического, причинно-следственного, расчета значений статистических показателей и m. д. Предложен перечень показателей, по значениям которых предлагается оценивать развитие процессов цифровизации. Сделан вывод о необходимости развития цифровой экономики в Российской Федерации и ее регионах. Представлен прогноз развития цифровой экономики в Екатеринбурге. Статья может быть полезна студентам высших учебных заведений, аспирантам, ученым-исследователям, специалистам, занимающимся разработкой (актуализацией) стратегий социально-экономического развития территорий, государственным и муниципальным служащим, а также иным заинтересованным лицам.
\end{abstract}

Ключевые слова:

город, цифровизация, цифровая экономика, стратегия, стратегическое планирование, стратеги ческое направление, стратегическая программа, стратегический проект.
Antipin Ivan Aleksandrovich

PhD in Economics, Associate Professor, Department of Regional, Municipal Economy and Management, Ural State University of Economics

\section{DIGITALIZATION AS A TRANSFORMING TOOL FOR THE STRATEGIC DEVELOPMENT OF THE TERRITORY [1]}

Summary:

The research considers digitalization as a tool for achieving and transforming the priorities for the strategic development of the territory. The paper presents the strategic targets and the development priorities of the Russian Federation. The possibilities of the digitalization processes development in the city of Yekaterinburg are investigated. The methodological basis of the study is based on the theoretical concepts of strategic management, regional and spatial economics. The approaches of Russian scientists to strategies and digital economy are ridentified by logical, dialectical, causal methods and the analysis of statistical indicators. A list of indicators is proposed to evaluate the development of digitalization processes. The study reveals the need to improve the digital economy in the Russian Federation and its regions. Growth forecast for the digital economy in Yekaterinburg is presented. The study can be useful for university and PhD students, researchers, experts devising (updating) the strategies for the social and economic development of the territories, public and municipal officials and other interested persons.

Keywords:

city, digitalization, digital economy, strategy, strategic planning, strategic area, strategic program, strategic project.

Стратегическая цель России, утвержденная в 2008 г., была сформулирована следующим образом: «...достижение уровня экономического и социального развития, соответствующего статусу России как ведущей мировой державы XXI в., занимающей передовые позиции в глобальной экономической конкуренции и надежно обеспечивающей национальную безопасность и реализацию конституционных прав граждан» [2].

В 2018 г. утверждены национальные цели развития Российской Федерации на период до 2024 г., одной из которых является «обеспечение ускоренного внедрения цифровых технологий в экономике и социальной сфере» [3].

В июле 2016 г. Советом при Президенте Российской Федерации по стратегическому развитию и приоритетным проектам был утвержден перечень основных направлений стратегического развития Российской Федерации до 2018 г. и на период до 2025 г. для формирования «пилотного» портфеля приоритетных проектов и программ (здравоохранение; образование; ипотека и арендное жилье; ЖКХ и городская среда; международная кооперация и экспорт; производительность труда; малый бизнес и поддержка индивидуальной предпринимательской инициативы; реформа контрольной и надзорной деятельности; безопасные и качественные дороги; моногорода; экология) [4]. В каждом из вышеназванных направлений предусмотрено выполнение соответствующих приоритетных проектов и программ. Аспекты цифровизации присутствуют, например, в таких приоритетных проектах, как: 
- «Совершенствование процессов организации медицинской помощи на основе внедрения информационных технологий» («Электронное здравоохранение»);

- «Внедрение автоматизированной системы мониторинга движения лекарственных препаратов от производителя до конечного потребителя для защиты населения от фральсифицированных лекарственных препаратов и оперативного выведения из оборота контрафактных и недоброкачественных препаратов» («Лекарства. Качество и безопасность»);

- «Современная цифровая образовательная среда в Российской Федерации» («Современная цифровая образовательная среда»);

- «Цифровая школа» [5].

В 2017 г. были утверждены Стратегия развития информационного общества в Российской Федерации на 2017-2030 гг. [6], а также государственная программа «Цифровая экономика Российской Федерации» [7].

Исследованием вопросов стратегического развития регионов и крупнейших городов автор занимается уже несколько лет [8]. В настоящее время существуют различные определения термина «стратегия» применительно к территориальному развитию, обратимся к некоторым из них. «Стратегия - это план-прогноз, интегрирующий в некое согласованное целое взаимообусловленные главные цели и задачи развития города, внутренние ресурсы, политику, определяющую поле деятельности и основные организационные действия (или, иначе, программы и проекты), направленные на достижение поставленных целей и не выходящие за пределы избранной городской политики» [9].

«Стратегия - разработанный на основе комплексного анализа внутренней и внешней среды, одобренный городским сообществом и институционально оформленный способ объединения существующих и потенциальных возможностей и ресурсов, реализация которых обеспечивает достижение основных целей городского развития» [10].

«Стратегия представляет собой детальный всесторонний комплексный план, предназначенный для того, чтобы обеспечить существование миссии объекта и достижение его целей» [11]. «Стратегия - это выбранное направление, вектор, путь дальнейшего развития, функционирование в рамках которого должно привести к достижению поставленных целей» [12].

Несмотря на научную разработанность вопросов стратегического планирования, в том числе муниципального, на практике существуют различные точки зрения на определение и сущность стратегии, не всегда верные, по мнению автора. Например, в стратегии Омска написано, что она разработана в соответствии с вопросами местного значения городского округа и полномочиями органов местного самоуправления [13]. Авторская точка зрения заключается в том, что в стратегии должно быть закреплено развитие всех процессов, происходящих на территории муниципального образования, независимо от полномочий, компетенций и т. д.

При формировании стратегии социально-экономического развития региона необходимо грамотно (оптимально) выстраивать приоритеты, а также механизмы и инструменты их достижения. Современными инструментами, трансформирующими достижение приоритетов стратегического развития в Российской Федерации на разных иерархических уровнях, являются цифровая экономика, цифровизация.

Понятие «цифровая экономика» относительно новое. Следствием этого является широкое использование терминов «цифровая экономика» и «цифровизация» без их четкого разграничения и единообразного толкования. Тем не менее в научной литературе существует немало подходов к раскрытию термина «цифровая экономика».

«Цифровая экономика - это коммуникационная среда экономической деятельности в сети Интернет, а также формы, методы, инструменты и результаты ее реализации» [14].

«Коммуникации, которые, в конце концов, и являются тем, что мы понимаем под цифровыми технологиями и средствами связи, - не просто сектор экономики. Коммуникации - это сама экономика» [15].

Автору близка позиция Р.В. Мещерякова, считающего, что существует два подхода к термину «цифровая экономика». Первый - «классический», согласно которому цифровая экономика - это экономика, основанная на цифровых технологиях, и при этом правильнее характеризовать исключительно область электронных товаров и услуг (телемедицина, дистанционное обучение, продажа медиаконтента и пр.). Второй - расширенный: цифровая экономика - это экономическое производство с использованием цифровых технологий (по данным интернет-портала МИА «Россия сегодня»).

В начале XX В. основными локомотивами мировой экономики были крупные нефтяные, металлургические, машиностроительные и горнодобывающие предприятия. В настоящее время крупнейшие мировые компании заняты цифровой экономикой (таблица 1). 
Таблица 1 - Рейтинг крупнейших компаний мира по версии аналитической компании Brand Finance, 2016 г. [16]

\begin{tabular}{|l|l|c|}
\hline \multicolumn{1}{|c|}{ Компания } & \multicolumn{1}{|c|}{ Основная соера деятельности } & $\begin{array}{c}\text { Капитализация, } \\
\text { млрд долл. США }\end{array}$ \\
\hline Apple & Производство электроники и информационных технологий & 577,4 \\
\hline Google & Интернет-сервисы, приложения, видеохостинг YоuTube & 547,9 \\
\hline Microsoft & Производство программного обеспечения & 443,0 \\
\hline Amazon & Торговля в интернете & 360,0 \\
\hline Wells Fargo & Банки & 299,0 \\
\hline Samsung & ПК, мобильные устройства, бытовая техника и электроника & 254,0 \\
\hline China Mobile & Телекоммуникации & 250,0 \\
\hline Verizon & Телекоммуникации & 229,0 \\
\hline AT\&T & Телекоммуникации & 226,0 \\
\hline Walmart & Ритейл & 216,9 \\
\hline
\end{tabular}

Предполагается, что фрормирование цифровой экономики способствует повышению экономической связности регионов и уменьшению уровня их социально-экономического неравенства [17].

Развитие цифровой экономики, цифровизации находит свое отражение и в документах стратегического планирования регионального и муниципального уровней. В частности, в городе Екатеринбурге процессы цифровизации предусматривались еще в первой редакции Стратегического плана. В пятом стратегическом направлении «Развитие транспорта, складского хозяйства и связи» присутствовала стратегическая программа «Связь - вызов века», состоящая из стратегических проектов «Башня - символ города», «Телефон для всех», «Доступный интернет (последняя миля)», «Информатизация муниципального образования “Город Екатеринбург”» [18].

В действующей (третьей) редакции Стратегического плана развития Екатеринбурга во втором стратегическом направлении «Екатеринбург - межрегиональный инновационно ориентированный промышленно-фринансовый центр» предусмотрена стратегическая программа «Цифровой Екатеринбург».

Цель стратегической программы «Цифровой Екатеринбург» - развитие направлений цифровой экономики, направленных на повышение эффрективности взаимодействия бизнеса, власти и общества, своевременное обеспечение информационно-коммуникативных сервисов современными инфраструктурными, институциональными, технологическими и кадровыми ресурсами [19]. Механизмами реализации должны стать два стратегических проекта - «Современная информационная среда» и «ІТ-кластер».

При разработке стратегической программы «Цифровой Екатеринбург» группой исследователей, в том числе и автором настоящей статьи, на основе обобщения существующих практик государственного и муниципального управления был разработан перечень показателей эффективности, по значениям которых предлагается оценивать развитие процессов цифровизации. Также были рассчитаны прогнозные значения предлагаемых показателей (таблица 2).

Следует отметить, что за последние годы процессы цифровизации в Екатеринбурге имеют положительную динамику [20]. Как показала практика, реализация проектов по повышению информационной открытости органов местного самоуправления существенно расширяет возможности для диалога с населением и представителями бизнес-сообщества, повышает качество и доступность муниципальных (государственных) услуг, способствует более эфрфективной реализации городской стратегии.

Прогнозируя результаты цифровизации российской экономики, следует отметить, что при грамотном распределении ресурсов она может стать важным источником долгосрочного экономического роста. Потенциальный эффект для ВВП России от цифровизации экономики к 2025 г. оценивается в 4,1-8,9 трлн р., что составляет 19-34 \% общего увеличения ВВП [21].

Можно назвать потенциальные источники прироста ВВП:

- оптимизация производственных и логистических операций,

- повышение эффективности рынка труда,

- повышение производительности оборудования,

- повышение эффеективности НИОКР и разработки продуктов,

- снижение расхода ресурсов и производственных потерь.

Дальнейшее развитие цифровой экономики призвано генерировать возможность трансформации пространственного развития страны в целом, снизить диффееренциацию между городами и регионами. 


\begin{tabular}{|c|c|c|c|c|c|c|}
\hline & 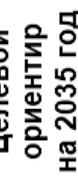 & ᄋ & రి & $\hat{\emptyset}$ & $\stackrel{\circ}{\leftarrow}$ & N \\
\hline & & $\infty$ & 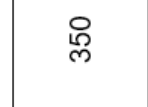 & छे & $\cong$ & $\begin{array}{l}0 \\
0 \\
0\end{array}$ \\
\hline & బั้ & $\varnothing$ & م् & ৪ & $\mp$ & 0 \\
\hline & & à & ৪্ল & ๑ & $\mp$ & 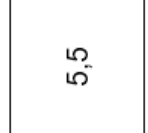 \\
\hline & N & ळ & $\stackrel{\circ}{\stackrel{N}{N}}$ & is & 으 & م \\
\hline & 空 & ஜ & : & $\hat{n}$ & 음 & $\stackrel{n}{\sim}$ \\
\hline & & $\infty$ & $\stackrel{\infty}{\sim}$ & 员 & 0 & $\nabla$ \\
\hline & 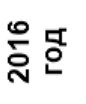 & $\check{\infty}_{\infty}$ & $\bar{్}$ & 1 & $\begin{array}{l}\infty \\
\infty \\
\infty\end{array}$ & $\hat{m}$ \\
\hline & 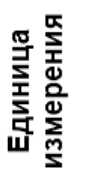 & ஃ̊ & 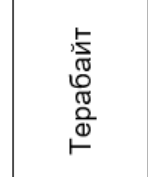 & ஃ̊ & ஃ̊ & ஃ̊ \\
\hline & 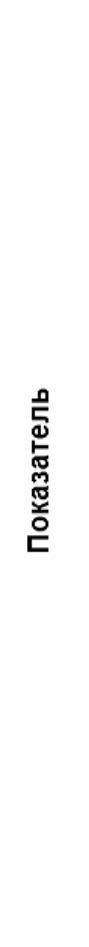 & 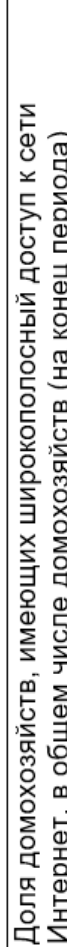 & 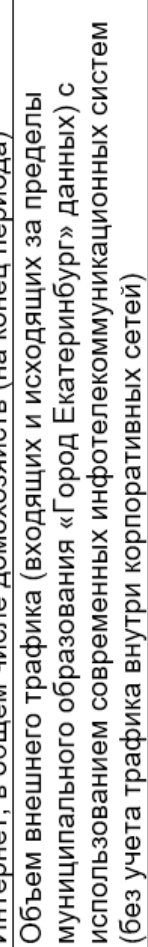 & 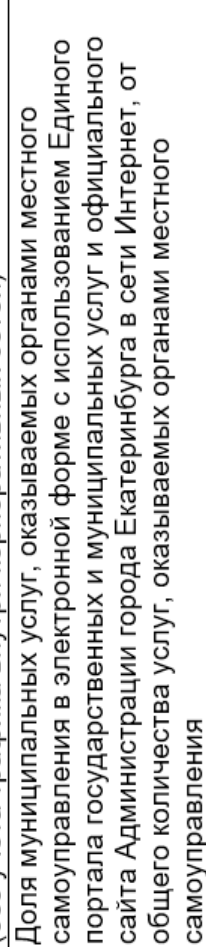 & 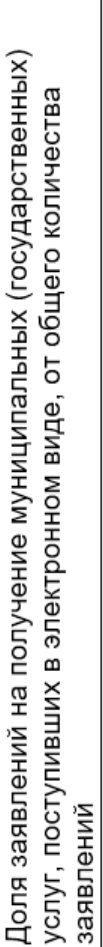 & 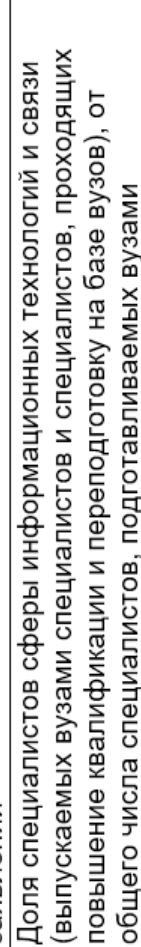 \\
\hline
\end{tabular}




\section{Ссылки и примечания:}

1. Статья подготовлена при фринансовой поддержке РФФИ в рамках научного проекта № 18-010-00789А «Разработка методологического инструментария исследования экономики нового индустриального города в условиях трансформации пространственной организации экономической деятельности».

2. О Концепции долгосрочного социально-экономического развития Российской Федерации на период до 2020 года [Электронный ресурс] : распоряжение Правительства Российской Федерации от 17 нояб. 2008 г. № 1662-р : ред. от 28 сент. 2018 г. Доступ из справ.-правовой системы «КонсультантПлюс».

3. О национальных и стратегических задачах развития Российской Федерации на период до 2024 г. [Электронный ресурс] : указ Президента Российской Федерации от 7 мая 2018 г. № 204. Доступ из справ.-правовой системы «КонсультантПлюс».

4. Федеральный проектный офис (Президиум Совета при Президенте Российской Федерации по стратегическому развитию и национальным проектам) [Электронный ресурс] // Правительство Poccии. URL: http://government.ru/department/410/projects/ (дата обращения: 18.11.2018).

5. Там же.

6. О Стратегии развития информационного общества в Российской Федерации на 2017-2030 годы [Электронный ресурс] : указ Президента РФ от 9 мая 2017 г. № 203. Доступ из справ.-правовой системы «КонсультантПлюс».

7. Об утверждении программы «Цифровая экономика Российской Федерации» [Электронный ресурс] : распоряжение Правительства Российской Федерации от 28 июля 2017 г. № 1632-р // Правительство России. URL: http://government.ru/docs/28653/ (дата обращения: 18.11.2018).

8. См., например: Антипин И.А. Мегаполис: формирование и развитие в старопромышленном регионе // Управленец. 2010. № 5-6 (9-10). С. 24-31; Прогноз развития крупнейшего города: конструирование инновационного будущего / Ю.Г. Лаврикова, А.А. Прядеин, И.А. Антипин, А.В. Суворова // Экономические и социальные перемены: факты, тенденции, прогно3. 2016. № 6 (48). С. 214-235. https://doi.org/10.15838/esc.2016.6.48.12.

9. Стратегия развития крупнейшего города: взгляд в будущее (научно-методический подход) / под науч. рук. Е.Г. Анимицы и В.С. Бочко. Екатеринбург, 2003. 455 с.

10. Фатхутдинов Р.А. Стратегический менеджмент : учебник. 7-е изд., испр. и доп. М., 2005. 448 с.

11. Уткин Э.А., Денисов А.Ф. Государственное и региональное управление : учеб. пособие. М., 2002. 320 с

12. Сурнина Н.М. Методы стратегического анализа и планирования на национальном, региональном и корпоративном уровнях (исследование конкретных ситуаций). Екатеринбург, 2004. 200 с.

13. О Стратегии социально-экономического развития города Омска до 2025 года [Электронный ресурс] : постановление администрации города Омска от 9 июля 2014 г. № 938-п. URL: https://docs.google.com/viewer?url=http\%3A\%2F\%2Fadmomsk.ru\%2Fc\%2Fdocument_library\%2Fget_file\%3Fp_I_id\%3D57791\%26folderld\%3D57882\%26name\%3DDLFE57018.pdf (дата обращения: 18.11.2018).

14. Калужский М.Л. Маркетинговые сети в электронной коммерции: институциональный подход. Изд. 2-е, перераб. и доп. М. ; Берлин, 2015. 402 с.

15. Kelly K. New Rules for the New Economy: 10 Radical Strategies for a Connected World. New York, 1999. 192 p.

16. Приведено по: Семячков К.А. Цифровая экономика и ее роль в управлении современными социально-экономическими отношениями [Электронный ресурс] // Современные технологии управления. 2017. № 8 (80). URL: https://sovman.ru/article/8001/ (дата обращения: 18.11.2018).

17. Годовой отчет о ходе реализации и оценке эффективности государственной программы Российской Федерации «Информационное общество (2011-2020 годы)» [Электронный ресурс] // Министерство цифрового развития, связи и массовых коммуникаций Российской Федерации. URL: https://digital.gov.ru/uploaded/files/otchet2016.pdf (дата обращения: 18.11.2018)

18. О стратегическом плане Екатеринбурга [Электронный ресурс] : решение Екатеринбургской городской думы от 10 июня 2003 г. № 40/6. Доступ из справ.-правовой системы «КонсультантПлюс».

19. О внесении изменений в решение Екатеринбургской городской думы от 10 июня 2003 г. № 40/6 «О стратегическом плане развития Екатеринбурга» [Электронный ресурс] : решение Екатеринбургской городской думы от 25 мая 2018 г. № 12/81// Екатеринбургская городская дума. URL: http://www.egd.ru/docs/acts/_aview_b6848 (дата обращения: 18.11.2018).

20. Итоги социально-экономического развития муниципального образования «Город Екатеринбург» в 2017 г. [Электронный ресурс]. Екатеринбург, 2018. URL: https://xn--80acgfbsl1azdqr.xn--p1ai/file/d8dafec2a0bdd06cd0d00f37014fc9b0 (дата обращения: 14.12.2018).

21. Цифровая экономика: глобальные тренды и практика российского бизнеса [Электронный ресурс] : электрон. изд. / отв. ред. Д.С. Медовников. URL: https://imi.hse.ru/data/2017/10/06/1159517769/!Цифровая\%20экономика\%20\%20глобальные\%20тренды\%20и\%20практика\%20российского\%20бизнеса.pdf (дата обращения: 18.11.2018).

22. О внесении изменений в решение Екатеринбургской городской думы от 10 июня 2003 г. № 40/6 «О стратегическом плане развития Екатеринбурга».

\section{References:}

Animitsa, EG \& Bochko, VS 2003, The Development Strategy of the Largest City: Glimpse into the Future (Scientific and Methodological Approach), Yekaterinburg, 455 p., (in Russian).

Antipin, IA 2010, 'Megalopolis: the Establishment and Development in the Old Industrial Region', Upravlenets, no. 5-6 (9-

10), pp. 24-31, (in Russian).

Fatkhutdinov, RA 2005, Strategic Management, textbook, 7th ed., Moscow, 448 p., (in Russian).

Kaluzhsky, ML 2015, Marketing Networks in E-Commerce: an Institutional Approach, 2nd ed., Moscow, Berlin, 402 p., (in Russian). Kelly, K 1999, New Rules for the New Economy: 10 Radical Strategies for a Connected World, New York, $192 \mathrm{p}$.

Lavrikova, YuG, Pryadein, AA, Antipin, IA \& Suvorova, AV 2016, 'Major City Development Forecast: Designing the Innovative

Future', Economic and Social Changes: Facts, Trends, Forecast, 2016, no. 6, pp. 214-235. https://doi.org/10.15838/esc.2016.6.48.12. Medovnikov, DS (ed.) 2018, Digital Economy: Global Trends and the Practical Issues of Russian Business, viewed 18 November 2018 <https://imi.hse.ru/data/2017/10/06/1159517769/!Цифровая\%20экономика\%20\%20глобальные\%20тренды\%20и\%20практика\%20российского\%20бизнеса.pdf>, (in Russian).

Semyachkov, KA 2017, 'Digital Economy and Its Role in the Modern Social and Economic Relations Management', Sovremennyye tekhnologii upravleniya, no. 8 (80), viewed 18 November 2018, <https://sovman.ru/article/8001/>, (in Russian). Surnina, NM 2004, Strategic Analysis and Planning at the National, Regional and Corporate Levels (Case Study), Yekaterinburg, 200 p., (in Russian).

The Results of the Social and Economic Development of the Yekaterinburg Municipality in 2017 2018, Yekaterinburg, viewed

14 December 2018, <https://xn--80acgfbs/1azdqr.xn--p1ai/file/d8dafec2a0bdd06cd0d00f37014fc9b0>, (in Russian). Utkin, EA \& Denisov, AF 2002, State and Regional Management, study guide, Moscow, 320 p., (in Russian). 